\title{
Swedish grouting design: hydraulic testing and grout selection
}

1 Åsa Fransson $\mathrm{PhD}$

Professor, Division of GeoEngineering, Chalmers University of Technology, Gothenburg, Sweden (corresponding author: asa.fransson@chalmers.se)

2 Johan Funehag $\mathrm{PhD}$

Assistant Professor, Division of GeoEngineering, Chalmers University of Technology, Gothenburg, Sweden
3 Johan Thörn PhD

Project leader, Division of GeoEngineering, Chalmers University of Technology, Gothenburg, Sweden
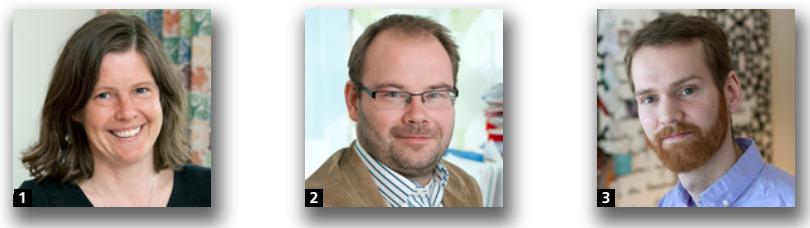

To ensure successful sealing of rock and soil, an adequate description of the system to be grouted is required as a basis for the grouting design and the selection of the grouting material. In rock, the individual fractures and the hydraulic apertures of these fractures form the basis of the Swedish grouting design concept. The hydraulic aperture is a key parameter when describing grouting behaviour and it is used to determine the extent to which the grout can enter fractures - that is, the penetrability. The hydraulic aperture also determines the penetration length, and therefore the grout parameters (e.g. yield stress and viscosity) as well as the grouting pressure and time needed to be adopted to the hydraulic aperture. Once these parameters are chosen, a suitable grouting technique can be adopted. Simple, practical rock and grout tests are important inputs to ensure correct design and performance. The aim of this paper is to present a testing procedure and provide examples from laboratory and field experience to demonstrate that the approach also works in practice.

\section{Notation}

$b \quad$ hydraulic aperture

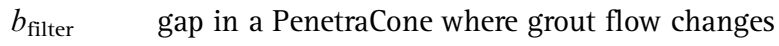
from continuous flow to dripping

$b_{\text {stop }} \quad$ gap in a PenetraCone where grout dripping ceases and the flow stops

$\mathrm{d} h_{\mathrm{w}} \quad$ difference in hydraulic head

$\mathrm{d} p_{\mathrm{w}} \quad$ difference in water pressure

$d_{95}$

g

$I$

$I_{\mathrm{D}}$

$I_{\max }$

$L$

$p_{\mathrm{w}}$

$p_{\mathrm{WPT}}$

$Q$

$Q_{\mathrm{NIM}}$

$Q_{\mathrm{WPT}}$ $T$ grain size below which 95\% of the grains fall acceleration due to gravity

penetration length

dimensionless penetration length

maximum penetration length

borehole distance

water pressure

injection pressure for a water pressure test (WPT) flow

flow, natural inflow measurement

flow, injection

transmissivity

\author{
grouting time \\ dimensionless grouting time \\ characteristic time \\ grouting overpressure (grouting pressure minus \\ water pressure) \\ parameter for estimating penetration length \\ viscosity of grout \\ viscosity of water \\ density \\ yield stress/strength
}

\section{Introduction}

Successful sealing of rock and soil requires an adequate description of the system to be grouted (e.g. Fransson, 2001a; Hernqvist et al., 2012; Kvartsberg, 2013) as a basis for the grouting design and the selection of the grouting material. When grouting fractured rock, the Lugeon value (e.g. Houlsby, 1990) has traditionally been used to describe the rock mass, although it describes neither the fractures nor the rock in a 
way that relates fully to the behaviour of the grout in the system. The basis for this Swedish grouting design concept comprises the individual fractures and the hydraulic apertures (b) of those fractures. The aperture is an important parameter when describing grouting behaviour and it is used to determine whether or not the grout can enter the fractures - that is, the penetrability. The aperture also determines the penetration length and in addition the grout parameters - for example, yield stress $\left(\tau_{0}\right)$ and viscosity $\left(\mu_{\mathrm{g}}\right)$; the grouting pressure and time are also important. Once these parameters are known, a suitable grouting technique can be adopted.

A design process for grouting was introduced by Gustafson et al. (2004) which is modified in Figure 1 (translated version, in Gustafson (2012)). The framework is grouting for waterproofing in crystalline rock, where the transmissivities of fractures can be assumed to follow a power-law distribution (few fractures dominate), which is also the context for this paper. The design process illustrated in Figure 1 includes (1) gathering in situ data and (2) estimating the transmissivity distribution (power law) among the fractures (4) generalising to an aperture distribution from which inflow to a tunnel can be estimated (6). Grout recipes are defined based on spread properties in (3) so that fracture apertures in (4) and fan geometry defined in (5) can be sealed to an extent that fulfils the desired maximum inflow in (6).

\subsection{Penetration length and grouting fan design}

The basis for the design concept presented here comprises the hydraulic apertures of individual fractures. Corresponding penetration lengths $(I)$ can be calculated from these apertures.
Figure 2 shows a diagrammatic sketch of a cross-section of a tunnel as well as a grouting fan intersecting a number of fractures of different lengths and apertures. The theoretical sealing of a fracture requires the borehole distance $L$ be less than twice the penetration length $I(L<2 I)$.

The equations used to estimate the penetration length of a Bingham fluid in a pipe and a parallel slot or a fracture with radial (two-dimensional (2D)) flow are derived in Gustafson et al. (2013). In the example below, Equations 1-6 and a graph (Figure 3) are used to estimate the penetration length for a cement-based grout (Bingham fluid). These equations are also described in Gustafson and Stille (2005), which is based on the manuscript later presented by Gustafson et al. (2013).

Gustafson et al. (2013) presented a comparison between experimental data and the estimated penetration length for 1D flow (a pipe or channel). There was good agreement. Further, initial investigations in a parallel plate fracture replica constructed at the Division of GeoEngineering at Chalmers University of Technology also show good agreement for radial (2D) flow (see video clip of flow in replica, Chalmers, 2014). This work is ongoing and will be developed and evaluated further.

As an example, Table 1 presents the yield stress $\left(\tau_{0}\right)$ and viscosity $\left(\mu_{\mathrm{g}}\right)$ of a grout as well as grouting overpressure $(\Delta p)$ (grouting pressure minus the groundwater pressure) and grouting time $(t)$ for the design of a grouting application for an investigation borehole performed at Äspö Hard Rock Laboratory, Äspö HRL, in December 2013. Due to a large

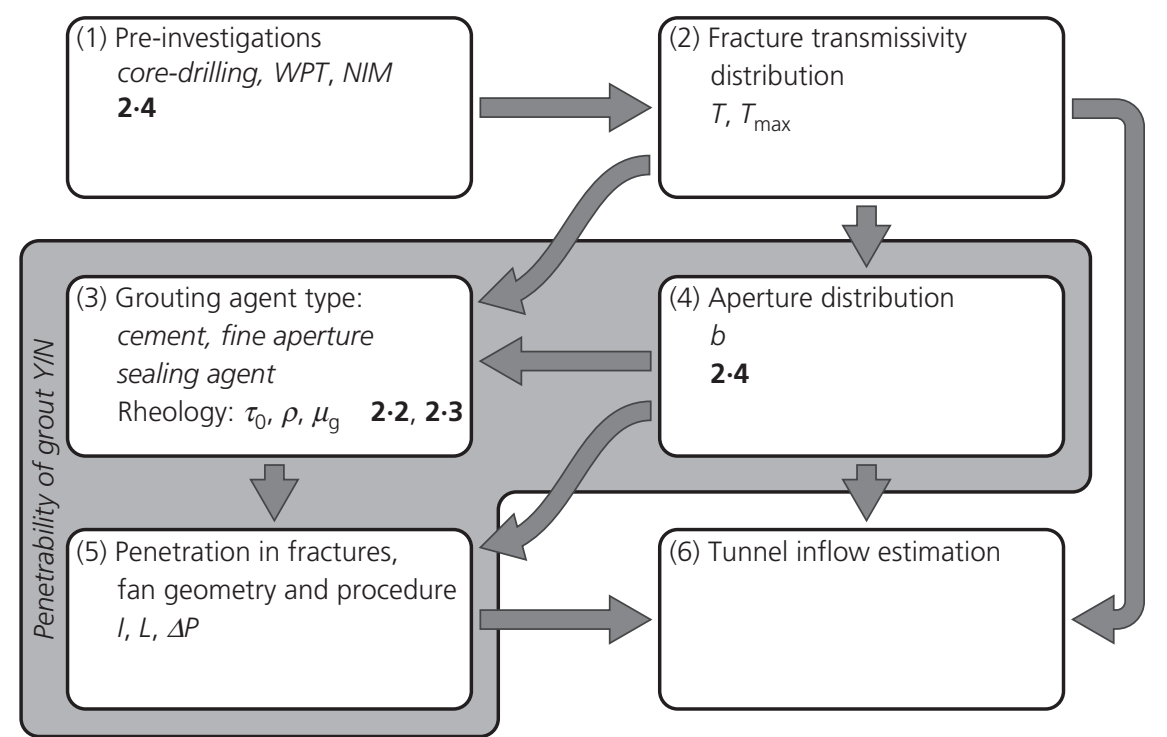

Figure 1. Flow chart for the design process for grouting, adapted from Gustafson et al. (2004). Each process box contain reference to the parameters of interest (italic) and a reference to the relevant section in this text (bold) 


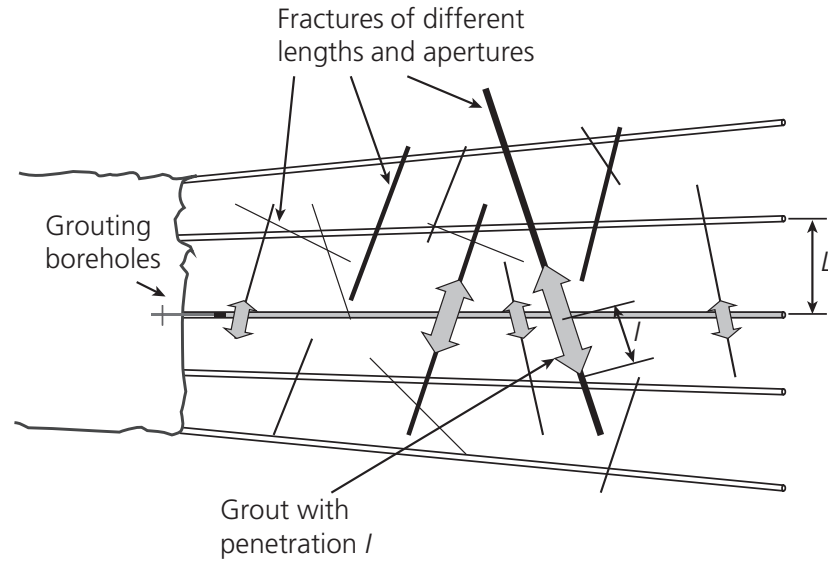

Figure 2. Cross-section of a tunnel and a grouting fan intersecting fractures. For the theoretical sealing of a fracture, the borehole distance $L$ should be less than twice the penetration length I $(L<2 I)$

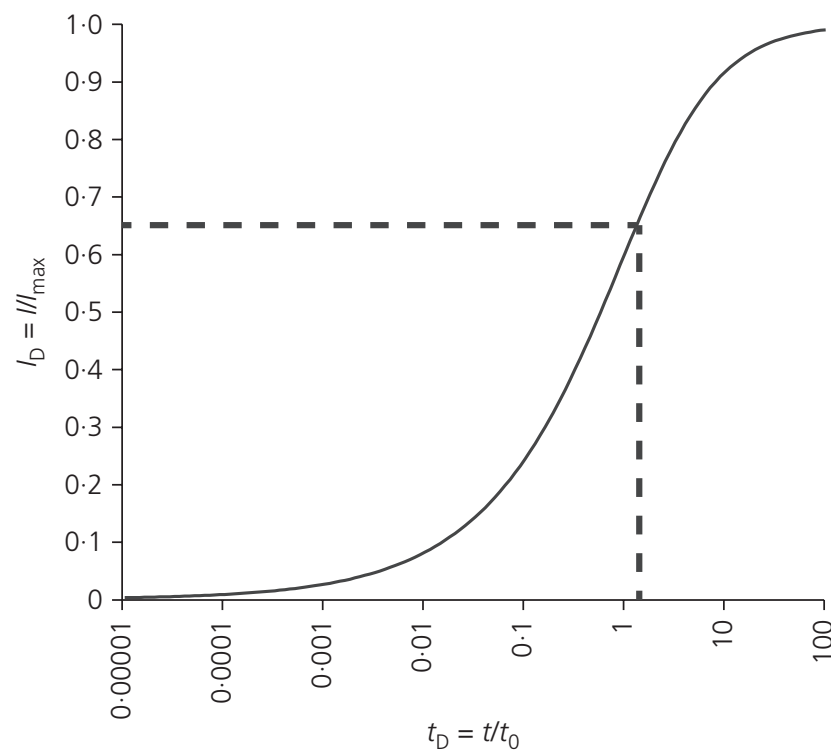

Figure 3. Penetration length and grouting time: $I / I_{\max }$ as a function of $t / t_{0}$ for a cement-based grout based on Gustafson et $a l$. (2013). For a $t_{D}$ of $1 \cdot 35, I_{D}$ is $\sim 0 \cdot 65$, meaning that $65 \%$ of the maximum penetration length is achieved

\begin{tabular}{lcccc}
\hline $\begin{array}{l}\text { Hydraulic } \\
\text { aperture, }\end{array}$ & $\begin{array}{r}\text { Yield } \\
\text { stress, } \\
\text { b: } \mu \mathrm{m}\end{array}$ & $\begin{array}{c}\text { Viscosity, } \\
\tau_{0}: \text { Pa }\end{array}$ & $\begin{array}{c}\text { Grouting } \\
\text { overpressure, } \\
\Delta p: \mathrm{MPa}\end{array}$ & $\begin{array}{c}\text { Grouting } \\
\text { time, } \\
t: \mathrm{min}\end{array}$ \\
\hline 250 & 15 & 0.015 & 5 & 45
\end{tabular}

Table 1. Input data for estimating penetration length: example from grouting design for an investigation borehole at Äspö HRL, Sweden inflow with a risk of influencing further investigations, the first $15 \mathrm{~m}$ of the borehole was grouted before drilling continued. The hydraulic characterisation that was used as a basis for the grouting design comprised inflow during drilling and transient hydraulic tests performed before grouting. The main inflow was found at a borehole length of $10.5 \mathrm{~m}$ and was initially $280 \mathrm{l} / \mathrm{min}$ and decreased to about $200 \mathrm{l} / \mathrm{min}$. The estimated hydraulic aperture was, in this case, $250 \mu \mathrm{m}$ (see Equation 7). Due to the high hydraulic head $(320 \mathrm{~m})$ and gradient, grouting design aimed at a stiff grout with a yield strength of $15 \mathrm{~Pa}$.

Using the data for the investigation borehole at Äspö HRL (Table 1), the following estimates of a maximum penetration length $I_{\max }$ and a characteristic time $t_{0}$ were obtained

1. $I_{\max }=\frac{\Delta p b}{2 \tau_{0}}=\frac{5 \times 10^{6} \times 250 \times 10^{-6}}{2 \times 15}=41.7 \mathrm{~m}$

2. $t_{0}=\frac{6 \Delta p \mu_{\mathrm{g}}}{\tau_{0}^{2}}=\frac{6 \times 5 \times 10^{6} \times 15 \times 10^{-3}}{15^{2}}=33.3 \mathrm{~min}$

The characteristic time is included in the graph, describing the dimensionless penetration length $I_{\mathrm{D}}=I / I_{\max }$ as a function of the dimensionless grouting time $t_{\mathrm{D}}=t / t_{0}$ (Figure 3 ). A grouting time $t$ of 45 min gives

3. $t_{\mathrm{D}}=\frac{t}{t_{0}}=\frac{45}{33 \cdot 3}=1 \cdot 35$

According to the graph (Figure 3), this results in a dimensionless penetration length $I_{\mathrm{D}}$ of $\sim 0 \cdot 65$. This means that, after 45 min of grouting, $65 \%$ of the maximum penetration length is achieved. This can also be estimated directly using equations behind the graph

4. $I_{\mathrm{D}} \approx \sqrt{\Theta^{2}+4 \Theta}-\Theta$ 
In the example above, sealing of an investigation borehole was the main objective so the actual penetration length was not the key issue. To obtain a theoretical overlap in a grouting fan, a borehole distance (at borehole tip) $L$ should be suggested so that $L<2 I$ (Figure 2). A common limit for what one can expect to seal with a cement-based grout is $50-100 \mu \mathrm{m}$ (Gustafson et al., 2009) and, in that case, $100 \mu \mathrm{m}$ would be used as the dimensioning aperture. As follows from Equation 1, a sufficient penetration length in this fracture would also result in the (theoretical) sealing of all fractures with larger apertures intersected by the boreholes.

A similar approach can be used for a Newtonian fluid such as silica sol (Butrón et al., 2012). Silica sol is a grouting agent that consists of nanospheres of amorphous silica dispersed in water. Mixing with a salt solution catalyses gelling of the material and the mixing proportions govern the gelling time (e.g. Funehag, 2007). Silica sol is modelled as a gelling Newtonian fluid that rheologically is only described by its viscosity development over time (i.e. no yield stress). To characterise the fluid for grouting purposes it is suggested here to use the initial viscosity $(\approx 0.005 \mathrm{~Pa} \cdot \mathrm{s})$ and the gel induction time (the time taken for the mix to reach the double the viscosity). Details of the different steps can be found in Funehag and Gustafson (2008).

Section 1 presented the procedure for estimating the penetration length for an investigation borehole and a grouting fan design using the 'expected' properties of a specific grout. The next step is to show how the parameters included in the above equations can be obtained by measuring the 'actual' properties of the grout.

\section{Hydraulic testing and grout selection}

The proposed methods used to characterise the fractured rock are short-duration hydraulic tests (of a few minutes) based on either inflow or injection of water. A graph that includes the hydraulic aperture has been developed to facilitate the selection of grout based on penetrability (see Section 2.4).

The grout properties are characterised in laboratory preinvestigations and from these investigations the grout type (e.g. cement-based grout or grout for fine-aperture sealing) with the desired properties can be selected. In the field, control measurements should be made to check that the expected properties are actually obtained. Methods used for testing the penetrability include the PenetraCone (Axelsson and Gustafson, 2010) and an invention referred to as the yield stick (Axelsson and Gustafson, 2006), which is used to test the yield stress and viscosity in combination with the traditional Marsh funnel and mud balance (e.g. API, 1990; Håkansson, 1993). The equipment is presented in Figure 4.
The testing procedure suggested is described further in the subsections below and includes the following.

Investigation of grout properties $\left(\mu_{\mathrm{g}}, \tau_{0}\right.$ and penetrability) in the laboratory.

- Estimation of the penetration length and adaptation of the borehole geometry.

- Checking grout properties in the field.

- Use of hydraulic tests in grouting boreholes as a basis for grout selection.

\subsection{PenetraCone - penetrability}

The PenetraCone is presented in Axelsson and Gustafson (2010). This device is used to measure the penetrability of cementitious grouts (Figures 4 and 5). The measuring device consists of two conical cylinders where a gap between the cones resembles the opening between parallel plates (a simplification of a fracture). The gap can be adjusted by turning the inner cone and it is measured using a dial indicator gauge attached to the inner cone. The measurement begins with a large open gap, and the gap is then reduced until the grout flow changes from continuously flowing to dripping $\left(b_{\text {filter }}\right)$, which indicates that filtration of the cement will begin. Measurement continues by reducing the gap until the dripping ceases and the flow stops completely $\left(b_{\text {stop }}\right)$.

In Axelsson and Gustafson (2010), six different grout mixes were used with water-to-solid ratios of $0.8-1.4$ and three different values of $d_{95}$, $(30,20$ and $16 \mu \mathrm{m}) . d_{95}$ is the grain size below which $95 \%$ of the grains fall. The ratio between $b_{\text {filter }}$ and $d_{95}$ of the grouts was in the range $1 \cdot 5-6 \cdot 5$ (the highest figure may be due to difficulty mixing the $16 \mu \mathrm{m}$ grout). For a water-to-cement ratio of 1.0 and above, the $b_{\text {stop }}$ to the grain size of the grout was $0 \cdot 5-1 \cdot 8$, whereas for a water-to-cement ratio of 0.8 this relationship was $2 \cdot 0-5 \cdot 0$. This indicates that the value of $b_{\text {stop }}$ is generally around the largest grain size of the grout except for the

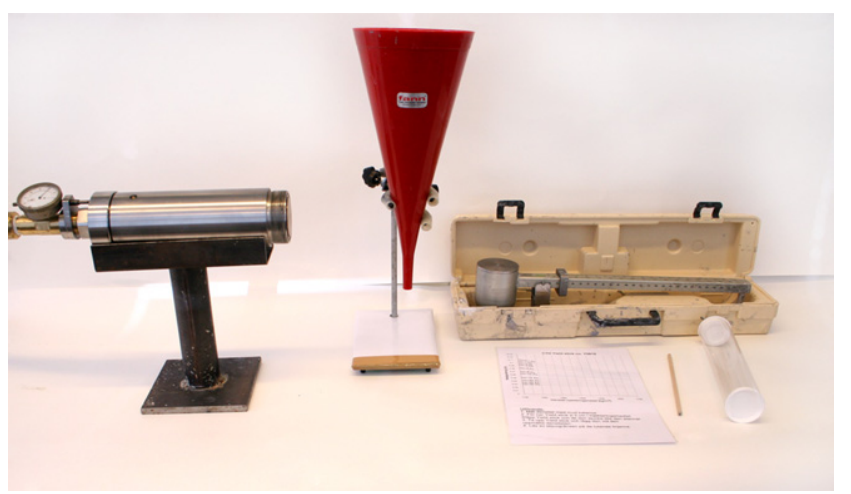

Figure 4. The four measurement devices. From the left, the PenetraCone, the Marsh funnel, the mud balance (at the back) and the yield stick, including the measurement graph (see also Figure 6) (picture by Nina Zanders) 


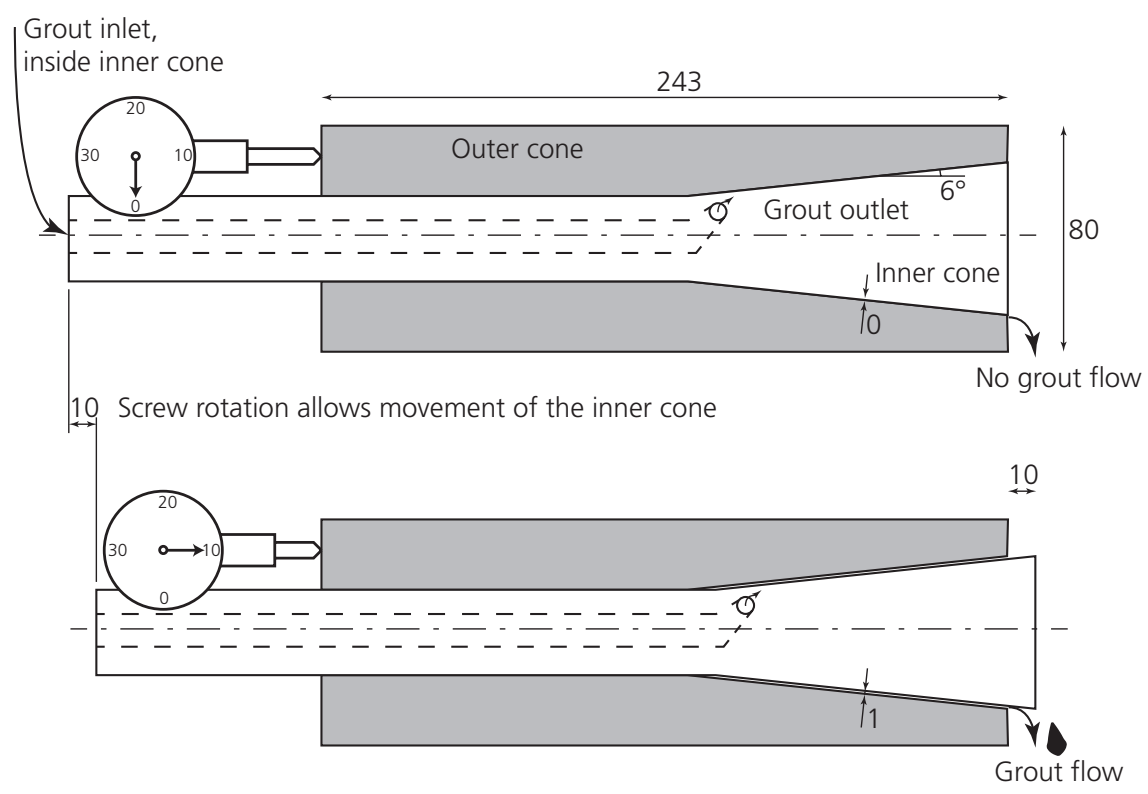

Figure 5. Sketch of the PenetraCone (dimensions in $\mathrm{mm}$ ).

Top: fully closed. Bottom: opened $10 \mathrm{~mm}$ rendering a $1 \mathrm{~mm}$ slot

for the grout to flow through

thicker grout mixes. The value of $b_{\text {filter }}$ should be related to the value of $b_{\text {critical }}$ obtained using a penetrability meter (or similar) since they both describe the initiation of the filtration process of a grout (e.g. Eklund and Stille, 2008).

Fransson (2009) and Gustafson et al. (2009) present how grout can be selected based on a fracture hydraulic aperture assessment and they argue that an effective fracture hydraulic aperture would appear to be useful for grout penetration. As an example, Gustafson et al. (2009) investigate the penetration of cementitious grout close to a penetration threshold using a variable aperture and a median (effective) hydraulic aperture that is successively decreased down to an assumed penetrability limit for the grout. This results in a local cluster only being filled with grout. For silica sol or other non-granular grouting materials that allow fine-aperture sealing, penetrability is not an issue since it can penetrate much smaller fracture apertures.

\subsection{Mud balance and yield stick - density and yield stress}

The 'density', or the specific gravity, is measured using a 'mud balance' (API Recommended Practice 13B-1 (API, 1990)). The mud balance is a balance scale with a $210 \mathrm{ml}$ cup and a piston with a rider attached. At equilibrium, the specific gravity is determined directly on the piston at the position of the rider. The device is well established and was originally developed for routine testing of drilling mud in the oil recovery industry.

The 'yield stick' is as described previously - a method for measuring the 'yield stress' of cementitious grouts and is presented

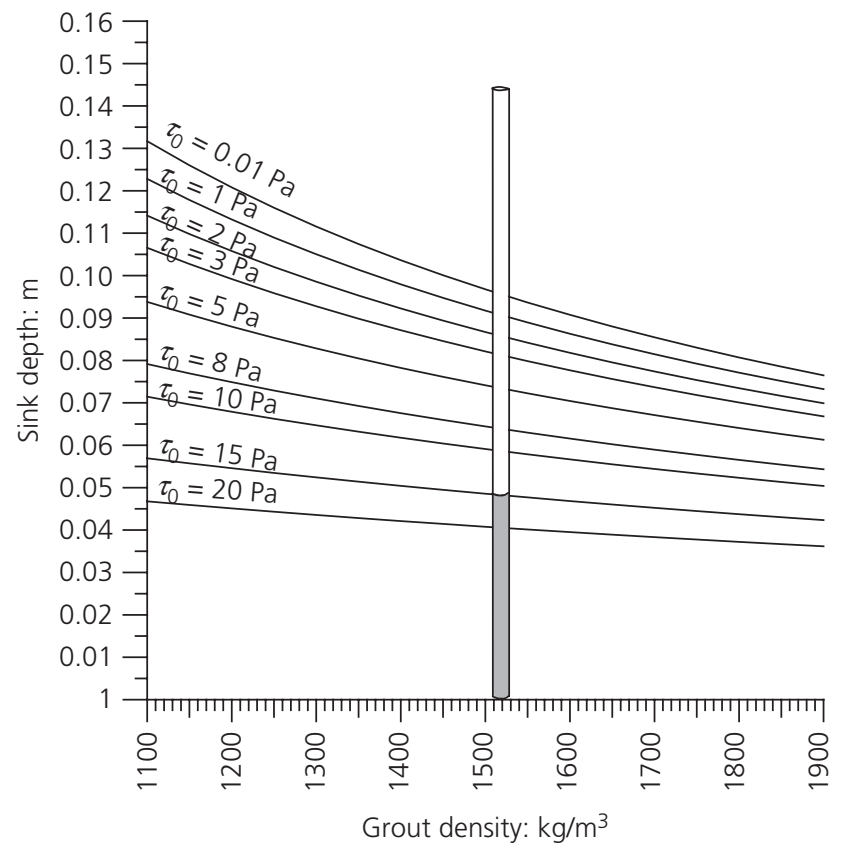

Figure 6. Measurement using the yield stick. The grey part of the stick shows the sink depth of the stick into the grout. In a grout with a density of $1520 \mathrm{~kg} / \mathrm{m}^{3}$, the yield stress for the tested grout can be determined directly as $15 \mathrm{~Pa}$

in Axelsson and Gustafson (2006) (Figures 4 and 6). They compare shear strengths obtained using the yield stick with shear strength measurements made using a rotational rheometer in the laboratory. The comparison shows good agreement. The 


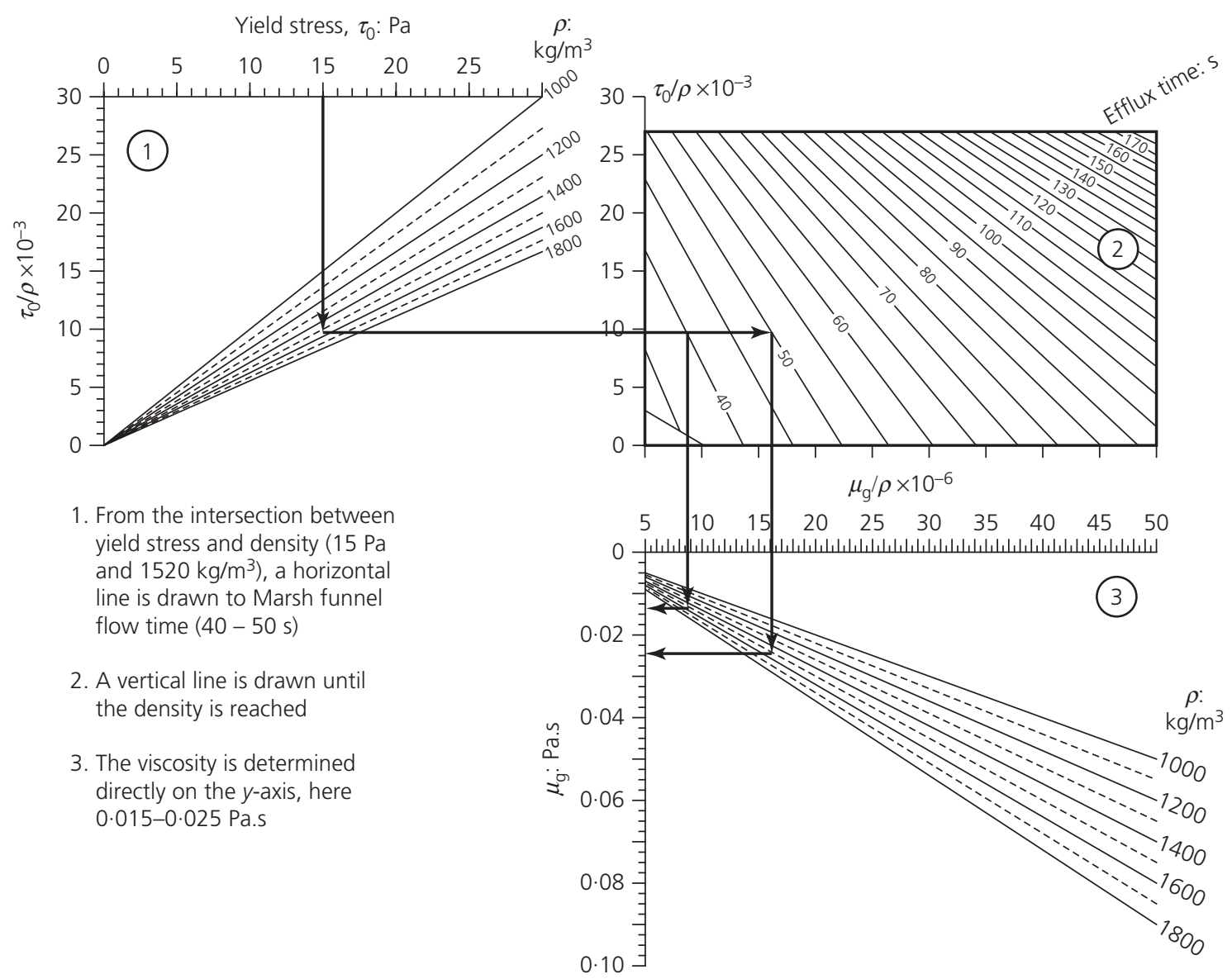

Figure 7. Example of measurement of viscosity using the known yield stress, density and Marsh funnel flow time. An example evaluation is shown with the arrows and notes $1-3$. Graph 2 is from Håkansson (1993)

yield stick has been used in the field as a tool to check that the desired properties are actually obtained.

The method consists of a stick with a controlled weight together with its specific measurement (and evaluation) sheet. The stick is placed in the grout and the sink depth is proportional to the yield stress of the grout. The measurement sheet and an example of a measurement using the stick are shown in Figure 6. By placing the stick on the measurement sheet, the yield stress can be determined directly. In the example shown in Figure 6, the density of the grout is $1520 \mathrm{~kg} / \mathrm{m}^{3}$ and the grey part on the stick represents the sink depth. The yield stress in this case would be $15 \mathrm{~Pa}$.

\subsection{Density, Marsh funnel flow time and yield stress - viscosity}

The text in Figure 7 describes steps 1-3 when estimating grout viscosity $\left(\mu_{\mathrm{g}}\right)$ from measurements using the yield stick, Marsh funnel and mud balance. In this example, the grout density is $1520 \mathrm{~kg} / \mathrm{m}^{3}$, the yield stress is $15 \mathrm{~Pa}$ and the Marsh funnel flow time (efflux time) is between 40 and $50 \mathrm{~s}$. The viscosity is determined directly on the $y$-axis and is found to be in the interval $0 \cdot 015-0 \cdot 025 \mathrm{~Pa} \cdot \mathrm{s}$.

The fluidity of grouts or the Marsh funnel flow time can be measured using the 'Marsh funnel'. There are different funnel variants, but in API Recommended Practice 13B-1 (API, 1990) a funnel with an outlet of $4.75 \mathrm{~mm}$ and a volume of 1.51 is used. The outflow time for 11 is measured.

The device can be checked to ensure the water has a flow time of $28 \mathrm{~s}$ (at $21^{\circ} \mathrm{C}$ ). Håkansson (1993) developed a graph showing the relationship between the Marsh funnel flow time and the viscosity (Graph 2, Figure 7). The graph was developed for a funnel with dimensions according to API 13B-1 and a volume of 11 . To calculate the viscosity, the density and the yield stress of the grout need to be known.

The rheological properties of grout are estimated here using basic tests. Interesting additional testing and follow up would 
be in-line measurements as suggested in, for example, Rahman et al. (2015).

\subsection{Hydraulic tests - hydraulic aperture}

Short-duration hydraulic tests in grouting boreholes with inflow or injection of water are used to characterise the fractured rock mass, see Figure 8. Further, Figure 9 shows a grout type selection graph based on penetrability (Fransson, 2009), including the flow $(Q)$, the difference in hydraulic head $\left(\mathrm{d} h_{\mathrm{w}}\right)$ and the estimated hydraulic aperture $(b)$, based on the cubic law (Snow, 1968)

7. $T=\frac{\rho \boldsymbol{g} b^{3}}{12 \mu_{\mathrm{w}}} \approx \frac{Q}{\mathrm{~d} h_{\mathrm{w}}}$

The transmissivity $(T)$, can be approximated by the specific capacity $\left(Q / \mathrm{d} h_{\mathrm{w}}\right)$, when using short-duration tests (Fransson, 2001b) such as a water pressure test (WPT) (ISO, 2012). Figure 9 also includes data (flow $Q$ and difference in head $\mathrm{d} h_{\mathrm{w}}$ ) from four Swedish experiments or construction projects (Table 2). Experiments and data are described further in the next section.

During a natural inflow measurement (NIM), the natural inflow $\left(Q_{\text {NIM }}\right)$ from an open borehole or a section of a borehole is measured (Figure 8). Before opening the borehole, the (stabilised, natural) water pressure $\left(p_{\mathrm{w}}\right)$ (herein $\mathrm{Pa}$ ) should be measured. The hydraulic aperture (assuming flow between two parallel plates) is calculated using Equation 8

8. $b \approx \sqrt[3]{\frac{Q_{\mathrm{NIM}}}{p_{\mathrm{w}}-0} 12 \mu_{\mathrm{w}}}=\sqrt[3]{\frac{Q_{\mathrm{NIM}}}{\mathrm{d} h_{\mathrm{w}}} \frac{12 \mu_{\mathrm{w}}}{\rho \boldsymbol{g}}}$

A WPT (Figure 8) is performed by injecting water into a borehole or a section of a borehole with pressure $p_{\mathrm{WPT}}(\mathrm{Pa})$. The
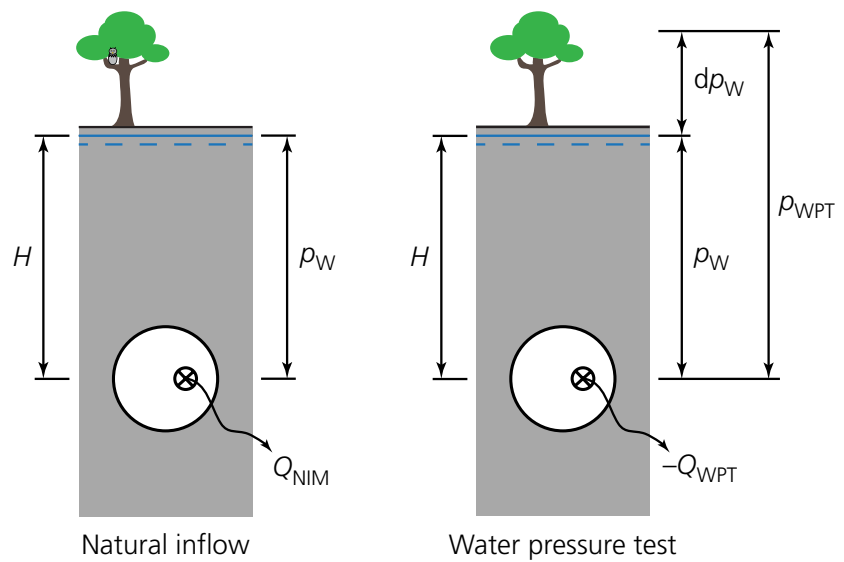

Figure 8. Sketches of NIM and WPT performed in a tunnel. Flow $Q$ and change in head $d h_{\mathrm{w}}=\mathrm{d} p_{\mathrm{w}} / \rho \boldsymbol{g}$ are measured in different ways. The pressure $p_{\mathrm{w}}(\mathrm{Pa})$ corresponds to the depth of the tunnel $H=p_{\mathrm{w}} / \rho \boldsymbol{g}$ injected flow is $Q_{\mathrm{WPT}}$. Before injecting water into the borehole, the (stabilised, natural) water pressure $p_{\mathrm{w}}(\mathrm{Pa})$ should be measured. The hydraulic aperture is calculated using Equation 9

$$
\text { 9. } \begin{aligned}
b & \approx \sqrt[3]{\frac{-Q_{\mathrm{WPT}}}{p_{\mathrm{w}}-p_{\mathrm{WPT}}} 12 \mu_{\mathrm{w}}}=\sqrt[3]{\frac{Q_{\mathrm{WPT}}}{p_{\mathrm{WPT}}-p_{\mathrm{w}}} 12 \mu_{\mathrm{w}}} \\
& =\sqrt[3]{\frac{Q_{\mathrm{WPT}}}{\mathrm{d} h_{\mathrm{w}}} \frac{12 \mu_{\mathrm{w}}}{\rho \boldsymbol{g}}}
\end{aligned}
$$

For hydraulic apertures larger than $100 \mu \mathrm{m}$, a regular Scandinavian grouting cement with a $d_{95}$ of about $30 \mu \mathrm{m}$ is expected to have full penetrability (type A, Figure 9) while for apertures smaller than $50-100 \mu \mathrm{m}$ the penetrability is limited. Knowing the flow (1/min) and the (difference in) hydraulic head $(\mathrm{m})$, the hydraulic aperture and type of grout are identified directly using the grout type selection graph (Figure 9). For the investigation borehole at Äspö HRL (Table 1), where penetration length was previously estimated, flow was $200 \mathrm{l} / \mathrm{min}$ and the hydraulic head was $320 \mathrm{~m}$. This would, as can be seen, result in an aperture of $250 \mu \mathrm{m}$ (Equation 7). For a pillar experiment in crystalline, fractured rock also at Äspö HRL (see Section 3 and Table 2), the flow $Q_{\text {WPT }}$ is $\sim 0 \cdot 11 / \mathrm{min}$ and the difference in head $\mathrm{d} h_{\mathrm{w}}$ is $25 \mathrm{~m}$, resulting in a hydraulic aperture of about $50 \mu \mathrm{m}$. These two are examples of fractures where penetrability plays a key role. For the $250 \mu \mathrm{m}$ aperture fracture, the grout $\left(d_{95}=30 \mu \mathrm{m}\right)$ was expected to penetrate easily. For the $50 \mu \mathrm{m}$ fracture a more limited penetration could be expected $\left(d_{95}=12 \mu \mathrm{m}\right)$.

\section{Examples from the laboratory and the field}

Several tunnelling projects have shown that using the hydraulic aperture as a basis for grout selection is a good approach. A general rule is that cementitious grouts can penetrate fractures that are around three times $d_{95}$ (e.g. Butrón et al., 2010; Martinet, 1998). The pillar experiment (Table 2 and Figure 9) performed at a depth of $\sim 100 \mathrm{~m}$ in crystalline rock at Äspö HRL (Eriksson, 2002; Fransson, 2001a; Funehag and Fransson, 2006) identifies a clear difference between the very limited penetration (penetrability) of a cement-based grout (micro-cement $d_{95}=12 \mu \mathrm{m}$ ) and the larger penetration for silica sol in a fracture with a hydraulic aperture of $50 \mu \mathrm{m}$. The results from another tunnel at Äspö HRL (TASQ) using a cement-based grout $\left(d_{95}=16 \mu \mathrm{m}\right)$ confirmed that fractures of around $50 \mu \mathrm{m}$ and larger, but not below $30 \mu \mathrm{m}$, had been sealed (Hernqvist et al., 2009). The limited penetration identified here suggests that $3 d_{95}$ may not be sufficient (here, $b / d_{95} \approx 4$ when $d_{95}$ is 12 and $16 \mu \mathrm{m}$, cf. Table 2). Previous results - for example, from Axelsson and Gustafson (2010) and Eklund and Stille (2008) - indicate that for grout with a small $d_{95}$, the minimum aperture (or slot) that can be grouted increases, possibly as an effect of aggregate formation. 


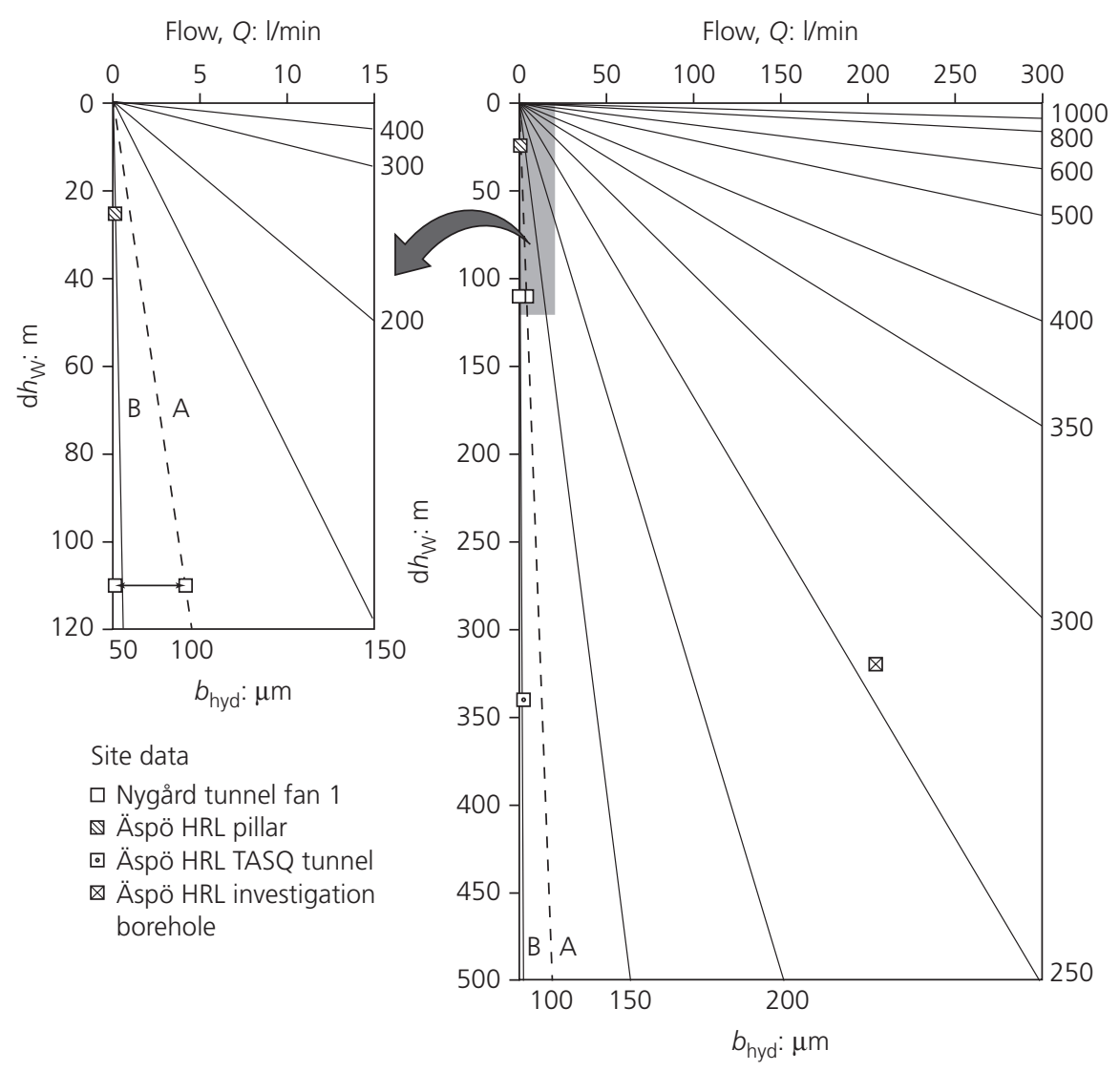

Figure 9. Grout type selection graph based on penetrability, including the flow $Q$, the change in head $\mathrm{d} h_{\mathrm{w}}(\mathrm{m})$, intervals of hydraulic aperture $b$ and grout types $A$ (e.g. a cement-based grout) and B (e.g. a grout for fine-aperture sealing). The broken line (here $100 \mu \mathrm{m}$ ) should be adapted to the grout types used. Data from the four sites included in Table 2 are also shown

\section{Depth: $\mathrm{m} \quad$ Flow, $Q: 1 / \mathrm{min} \quad \mathrm{d} h_{\mathrm{w}}: \mathrm{m} \quad$ Grouting Hydraulic $\quad$ Penetrability: $\quad b / d_{95}$ pressure, aperture, comments}
p: MPa
b: $\mu \mathrm{m}$

\begin{tabular}{|c|c|c|c|c|c|c|c|}
\hline Äspö HRL pillar & 100 & $0 \cdot 1$ & 25 & $0 \cdot 2-0 \cdot 4^{a}$ & $\approx 50$ & $\begin{array}{l}\text { Very limited } \\
d_{95}: 12 \mu \mathrm{m}\end{array}$ & 4 \\
\hline Äspö HRL TASQ (tunnel) & 450 & $2 \cdot 5$ & 340 & $\Delta p: 1-2$ & $\approx 60$ & $\begin{array}{l}>50 \mu \mathrm{m} \text { but not } \\
\text { below } 30 \mu \mathrm{m} \\
d_{95}: 16 \mu \mathrm{m}\end{array}$ & 4 \\
\hline Nygård (tunnel) & 50 & $0 \cdot 1-4 \cdot 2$ & 110 & $2 \cdot 5^{\mathrm{a}}$ & $<100$ & $\begin{array}{l}\text { Very limited } \\
d_{95}: 30 \mu \mathrm{m}\end{array}$ & 3 \\
\hline Äspö HRL investigation borehole & 420 & 200 & 320 & $8 \cdot 2$ & $\approx 250$ & $\begin{array}{l}\text { Good } \\
d_{95}: 30 \mu \mathrm{m}\end{array}$ & 8 \\
\hline
\end{tabular}

\section{aLow water pressure: grouting pressure close to grouting overpressure}

Table 2. Input data: examples from four Swedish experiments/projects. Three with small hydraulic apertures and very limited penetrability and one with good penetrability and large hydraulic aperture. A $b / d_{95}$ ratio of about three is assumed to result in limited penetrability 
Another example that points in the same direction is the Nygård tunnel in south-west Sweden (Butrón et al., 2010; Gustafson et al., 2008), where all the boreholes in one of the investigated grouting fans had estimated hydraulic fracture apertures below $100 \mu \mathrm{m}$. The main grouting-induced reduction in transmissivity was seen in the roof, where silica sol was used. Only a minor reduction was identified in the boreholes in the floor of the tunnel where a cement-based grout was used $\left(d_{95}=30 \mu \mathrm{m}\right)$. A conclusion drawn from these projects is that fractures with an estimated hydraulic fracture aperture below $50-100 \mu \mathrm{m}$ are not likely to be groutable with a cement-based grout. This conclusion is supported by a grouting test in the fracture replica at Chalmers University of Technology, where practically no penetration was achieved at an aperture setting of $80 \mu \mathrm{m}$ using a grout with $d_{95}=30 \mu \mathrm{m}\left(3 d_{95}=90 \mu \mathrm{m}\right)$. To improve the result, a grout for fine-aperture fractures is suggested.

For the investigation borehole at Äspö HRL, a $250 \mu \mathrm{m}$ fracture aperture was estimated and this was expected (and found) to be groutable with a grout having a $d_{95}$ of $30 \mu \mathrm{m}$ $\left(3 d_{95}=90 \mu \mathrm{m}\right)$. In this case, a stiff cement-based grout comprising Injektering 30 (ordinary Portland cement with $d_{95}=30 \mu \mathrm{m}$ ) and GroutAid (an additive to cement made of silica fume dispersed in water that acts as an accelerator) was injected into the borehole. The recipe selected was the one utilised in a tunnel at Äspö HRL in 2008 that was developed to obtain a low pH $(<11)$ in the leachate (Bodén and Sievänen, 2005). A decrease in flow from over $2001 / \mathrm{min}$ to less than $11 /$ min was achieved. For the investigation borehole, key grouting aspects were penetrability (the ability of the grout to enter the fracture), grout penetration and erosion due to the high gradient.

In three of the four cases in Table 2, fairly low grouting pressures were used to reduce the risk of jacking the fractures. However, analyses of grouting data for the Nygård tunnel indicate that there is a risk of fractures opening if high pressures are used (Fransson et al., 2010). Due to the high rock stresses at the considerable depth of the TASQ tunnel, such deformations would mainly be expected close to the tunnel. The grouting pressure for the grouting of the investigation borehole was fairly high ( 82 bars $(8200 \mathrm{kPa}))$ but the depth of the tunnel suggests that rock stresses are high. The design and selection process presented here assumes constant (non-deformable) fracture apertures (Gustafson et al., 2013).

Works performed at Chalmers University of Technology in Gothenburg (e.g. Axelsson, 2009; Funehag, 2007; Funehag and Gustafson, 2008; Gustafson et al., 2013) and at the Royal Institute of Technology in Stockholm (e.g. Eklund and Stille, 2008; Eriksson, 2002; Håkansson, 1993; Hässler, 1991) show that the developed theories can be used to estimate the penetration length for both a gelling Newtonian fluid such as silica sol and a cement-based grout with Bingham fluid properties.
This paper deals with grouting of sparsely or moderately fractured rock, and in this case a radial flow approach as presented here is reasonable. For a densely fractured rock, or a soil, a 3D flow system is likely to be a better description and the grouted volume would also be related to this type of system (e.g. Sturk et al., 2013). In both cases, the maximum penetration can be described using the equilibrium between grout pressure and friction against the surrounding medium (e.g. Axelsson et al., 2009; Gustafson et al., 2013; Hässler, 1991; Kutzner, 1996). Water-bearing fracture systems like those above could be referred to as being different hydrogeological settings, and awareness of the flow dimension of the system at hand is key when designing grouting work.

The concept presented here includes a fracture aperture estimated from hydraulic tests as a key component. Comparing this approach directly with other methods - for example, grouting intensity number (GIN) (Lombardi and Deere, 1993), which involves grouting pressure and volume of grout - is difficult since they have different parameter set ups. The GIN can be related to a penetration length $(I)$, introducing a factor $K$ referred to as a groutability factor (e.g. Brantberger et al., 2000). In Brantberger et al. (2000), this factor is used to take into account the influence of geology by incorporating the assumed number of fractures using grout and the proportion of them being open. Another way to describe the geological material is to use the Lugeon value (e.g. Houlsby, 1990). This is defined as the loss of water in litres per minute and per metre borehole at an overpressure of $1 \mathrm{MPa}$. This gives a result of an average value describing the ability of the geological material to transmit water but describes neither the rock mass nor the fractures. The work presented here aims at a relevant physical representation of fractured crystalline rock that can capture penetrability and penetration length in fractures having a power-law size distribution.

The field measurement methods presented here are a combination of well-established methods and more recently developed methods. All tests have been performed as part of field tests for the TASS tunnel at Äspö HRL (Funehag and Emmelin, 2010). The results are promising and the different test methods have been tested separately in other experiments and tunnelling projects.

\section{Conclusions}

In this paper, the importance of using an understanding of the fracture system to be grouted as a basis for selecting a grouting design is highlighted. An adequate design can be produced using the relevant parameters and focusing on the requirements set for the particular tunnel. The important inputs for both design and performance are simple, practical tests on the rock and the grout. This paper presents a testing procedure and provides examples from laboratory and field experience that show that the approach works. 


\section{Acknowledgements}

The authors express their appreciation to the Royal Institute of Technology in Stockholm, Sweden, for their collaboration and to the Swedish Nuclear Fuel and Waste Management Co. SKB and the Äspö HRL for supporting experiments and providing valuable data. They are also grateful for financial support provided over the years and for valuable help from their division. They are truly grateful to Professor Gunnar Gustafson, who is no longer with them.

\section{REFERENCES}

API (American Petroleum Institute) (1990) Recommended Practice for Field Testing Water-Based Drilling Fluids. American Petroleum Institute, Washington, DC, USA.

Axelsson M (2009) Prevention of Erosion of Fresh Grout in Hard Rock. PhD thesis, Chalmers University of Technology, Gothenburg, Sweden.

Axelsson M and Gustafson G (2006) A robust method to determine the shear strength of cement-based injection grouts in the field. Tunnelling and Underground Space Technology 21(5): 499-503.

Axelsson M and Gustafson G (2010) The PenetraCone, a new robust field measurement device for determining the penetrability of cementitious grouts. Tunnelling and Underground Space Technology 25(1): 1-8.

Axelsson M, Gustafson G and Fransson Å (2009) Stop mechanism for cementitious grouts at different water-tocement ratios. Tunnelling and Underground Space Technology 24(4): 390-397.

Bodén A and Sievänen U (2005) Low-pH Injection Grout for Deep Repositories. Summary Report from a Co-Operation Project between NUMO (Japan), Posiva (Finland) and $S K B$ (Sweden). Swedish Nuclear Fuel and Waste Management Company, Stockholm, Sweden, SKB-Report R-05-40.

Brantberger M, Stille $\mathrm{H}$ and Eriksson M (2000) Controlling grout spreading in tunnel geometry - analyses and development of the GIN-method. Tunnelling and Underground Space Technology 15(4): 343-352.

Butrón C, Gustafson G, Fransson Å and Funehag J (2010) Drip sealing of tunnels in hard rock: a new concept for the design and evaluation of permeation grouting. Tunnelling and Underground Space Technology 25(2): 114-121.

Butrón C, Gustafson G and Funehag J (2012) A Swedish grouting design concept: grouting with silica sol in the Nygård and Törnskog tunnels. Proceedings of the 4th International Conference on Grouting and Deep Mixing, New Orleans, LA, USA. American Society of Civil Engineers, Reston, VA, USA, pp. 826-835.

Chalmers (2014) Hydrogeology and Grouting. Chalmers University of Technology, Gothenburg, Sweden. See http://www.chalmers.se/hydrogeology-grouting (accessed 03/02/2014).
Eklund D and Stille H (2008) Penetrability due to filtration tendency of cement-based grouts. Tunnelling and Underground Space Technology 23(4): 389-398.

Eriksson M (2002) Grouting field experiment at the Äspö Hard Rock Laboratory. Tunnelling and Underground Space Technology 17(3): 287-293.

Fransson Å (2001a) Characterisation of a fractured rock mass for a grouting field test. Tunnelling and Underground Space Technology 16(4): 331-339.

Fransson Å (2001b) Characterisation of Fractured Rock for Grouting Using Hydrogeological Methods. PhD thesis, Chalmers University of Technology, Gothenburg, Sweden.

Fransson Å (2009) Selection of grouting material based on a fracture hydraulic aperture assessment. Proceedings of the Nordic Symposium of Rock Grouting, Helsinki, Finland, pp. 55-61.

Fransson Å, Tsang CF, Rutqvist J and Gustafson G (2010) Estimation of deformation and stiffness of fractures close to tunnels using data from single hole hydraulic testing and grouting. International Journal of Rock Mechanics and Mining Sciences 47(6): 887-893.

Funehag J (2007) Grouting Fractured Rock with Silica Sol Grouting Design Based on Penetration Length. PhD thesis, Chalmers University of Technology, Gothenburg, Sweden.

Funehag J and Emmelin A (2010) Injektering av TASS-tunneln. Design, genomförande och resultat frän förinjekteringen. Swedish Nuclear Fuel and Waste Management Company, Stockholm, Sweden, SKB-Report R10-39 (in Swedish).

Funehag J and Fransson $\AA$ (2006) Sealing narrow fractures with a Newtonian fluid: model prediction for grouting verified by field study. Tunnelling and Underground Space Technology 21(5): 492-498.

Funehag J and Gustafson G (2008) Design of grouting with silica sol in hard rock - new methods for calculation of penetration length, part I. Tunnelling and Underground Space Technology 23(1): 1-8.

Gustafson G (2012) Hydrogeology for Rock Engineers. BeFo, Stockholm, Sweden.

Gustafson G and Stille H (2005) Stop criteria for cement grouting. Felsbau 25(3): 62-68.

Gustafson G, Fransson Å, Funehag J and Axelsson M (2004) Ett nytt angreppssätt för bergbeskrivning och analysprocess för injektering. Väg och Vattenbyggaren 2004(4): 10-15 (in Swedish).

Gustafson G, Butron C and Fransson Å (2008) Characterisation of the hydraulic properties of fractured rock from grouting data. Proceedings of the XXXVI IAH Congress, Toyama, Japan, pp. 1721-1728.

Gustafson G, Fransson Å, Butron C and Hernqvist L (2009) Effective fracture aperture for grout penetration. Proceedings of the Nordic Symposium of Rock Grouting, Helsinki, Finland, pp. 143-152.

Gustafson G, Claesson J and Fransson ^̊ (2013) Steering parameters for rock grouting. Journal of Applied Mathematics 2013, Article ID 269594. 
Håkansson U (1993) Rheology of Fresh Cement-Based Grouts. $\mathrm{PhD}$ thesis, Royal Institute of Technology, Stockholm, Sweden.

Hässler L (1991) Grouting of Rock - Simulation and Classification. Doctoral thesis, Royal Institute of Technology, Stockholm, Sweden.

Hernqvist L, Fransson Å, Gustafson G et al. (2009) Analyses of the grouting results for a section of the APSE tunnel at Äspö Hard Rock Laboratory. International Journal of Rock Mechanics and Mining Sciences 46(3): 439-449.

Hernqvist L, Kvartsberg S, Fransson Å and Gustafson G (2012) A Swedish grouting design concept: decision method for hard rock tunneling. Proceedings of the 4th International Conference on Grouting and Deep Mixing, New Orleans, LA, USA. American Society of Civil Engineers, Reston, VA, USA, pp. 816-825.

Houlsby AC (1990) Construction and Design of Cement Grouting: A Guide to Grouting in Rock Foundations. Wiley, New York, NY, USA.

ISO (International Organization for Standardization) (2012)

ISO 22282-3:2012: Geotechnical investigation and testing - geohydraulic testing - part 3: water pressure tests in rock. ISO, Geneva, Switzerland.
Kutzner C (1996) Grouting of Rock and Soil. Balkema, Rotterdam, the Netherlands.

Kvartsberg S (2013) On the Use of Engineering Geological Information in Rock Grouting Design. Licentiate thesis, Chalmers University of Technology, Gothenburg, Sweden.

Lombardi G and Deere D (1993) Grouting design and control using the GIN-principle. Water Power and Dam Construction 45(6): 15-22.

Martinet P (1998) Flow and Clogging Mechanisms in Porous Media with Applications to Dams. Doctoral thesis, Royal Institute of Technology, Stockholm, Sweden.

Rahman M, Håkansson U and Wiklund J (2015) In-line rheological measurements of cement grouts: effects of water/cement ratio and hydration. Tunnelling and Underground Space Technology 45(January): 34-42.

Snow DT (1968) Rock fracture spacings, openings, and porosities. Journal of the Soil Mechanics and Foundations Division: Proceedings of the American Society of Civil Engineers 94(January): 73-91.

Sturk R, Striberger J, Stille B and Aurell O (2013) Grouting operations in complex and heavily water bearing ground an analysis and summary from the Hallandsås project. Proceedings of the 7th Nordic Grouting Symposium, Gothenburg, Sweden, pp. 29-43. 